\title{
Structural characteristics and enhanced mechanical and thermal properties of full biodegradable tea polyphenol/poly(3-hydroxybutyrate-co-3-hydroxyvalerate) composite films
}

\author{
H. X. Xiang, S. H. Chen, Y. H. Cheng, Z. Zhou, M. F. Zhu* \\ State Key Laboratory for Modification of Chemical Fibers and Polymer Materials, and College of Materials Science and \\ Engineering, Donghua University, 201620 Shanghai, P.R.China
}

Received 20 April 2013; accepted in revised form 2 June 2013

\begin{abstract}
Full biodegradable poly(3-hydroxybutyrate-co-3-hydroxyvalerate) (PHBV) composite films were prepared with $5 \sim 40 \mathrm{wt} \%$ green tea polyphenol (TP) as toughener. The effects of mixing TP on mechanical properties, thermal properties and hydrophilic-hydrophobic properties of composite films were investigated. Tension test results show that the incorporation of TP in the PHBV matrix can enhance the toughness of the composite films. Differential scanning calorimetric (DSC) studies show that there is a single glass transition temperature and the lower melting point temperature. Fourier transform infrared (FT-IR) results confirm that the intermolecular hydrogen bonding interactions in composite films. Contact angle measurements show that the hydrophilicity of TP/PHBV composite films can be controlled through adjusting the composition of TP.
\end{abstract}

Keywords: biodegradable polymers, poly(hydroxybutyrate-co-hydroxyvalerate), tea polyphenol, mechanical properties, thermal properties

\section{Introduction}

Recently, bacterial polyester poly(hydroxybutyrateco-hydroxyvalerate) (PHBV) has been arising much attention in the field of biomedical and environmental friendly materials because of its good biocompatibility, biodegradability as well as thermoplastic properties. However, the wide application has been restricted by the poor mechanical properties and narrow processing window [1]. Therefore, a significant amount of work has been devoted to improving mechanical and thermal properties of PHBV via PHBV-based polymer blends and composites [2]. This work mainly covers four aspects: nanoparticles/PHBV composites, traditional petrochemicalbased materials/PHBV composites, biodegradable petrochemical-based polymer/PHBV composites, and bio-based materials/PHBV composites.

In nanoparticles/PHBV composites, inorganic nanoparticles mainly include oxide [3], nitride [4], mineralization materials $[5,6]$, carbon materials or minerals [7], and layered double hydroxides [8,9]. Organic nanoparticles mainly include cellulose nanocrystal [10], chitosan nanocrystal and starch nanocrystal [11]. The introduction of nanoparticles is helpful for improving the physical properties and processing properties of PHBV through increasing the nucleation density and decreasing the spherulite size. In petrochemical-based materials/PHBV composites, the additive components consist mainly of non-biodegradable polyolefin [12], polyurethane

\footnotetext{
${ }^{*}$ Corresponding author, e-mail: zhumf@dhu.edu.cn

(C) BME-PT
} 
elastomer [13] polyaniline [14]. These blending composites can improve physical properties by some extent and reduce the cost, but also there are some problems in compatibility. So Sadik improved the interfacial and mechanical properties of the immiscible PP/PHBV and PE/PHBV blends by preformed copolymer EVOH-g-PHBV [12]. In biobased materials/PHBV composites, thermoplastic starch, cellulose, polycaprolactone [15], xylogen [16], polylactic acid [17], PBAT [18] and poly (butylenes succinate) [19] are widely applied to fully biodegradable products [20,21].

In the method of toughening PHBV, bisphenol A (BPA) as one prominent modifiers, it deters the biodegradability and biocompatibility of PHBV. In order to solve the environmental pollution fundamentally, bio-based materials/PHBV composites are the main direction. As a bio-based material, tea polyphenol (TP) deriving from natural tea leaves is a kind of phenolic compound which contains multiple hydroxyl groups [22]. So fully biodegradable TP was chosen to replace BPA. The major component of TP is catechin, and its chemical structure is shown in Figure 1. This structure provides a large amount of phenolic hydroxyl groups in protondonating TP and allows it to take advantages of inhibiting bacterium, cancer, tumors.

Herein, fully biodegradable TP/PHBV composite films were prepared via solution blending and spin coating method with hydrogen bonding interaction with 5 40 wt $\%$ green TP as proton donor and biopolyester PHBV as proton acceptor. The tensile properties of composite films were studied to investigate the toughening effect of TP on PHBV matrix. The physical properties, thermal properties, crystalline structure and morphology were characterized by Fourier transform infrared spectroscopy (FTIR), differential scanning calorimetry (DSC), polarization optical microscopy (POM) and wide angle X-ray diffraction (WXRD).

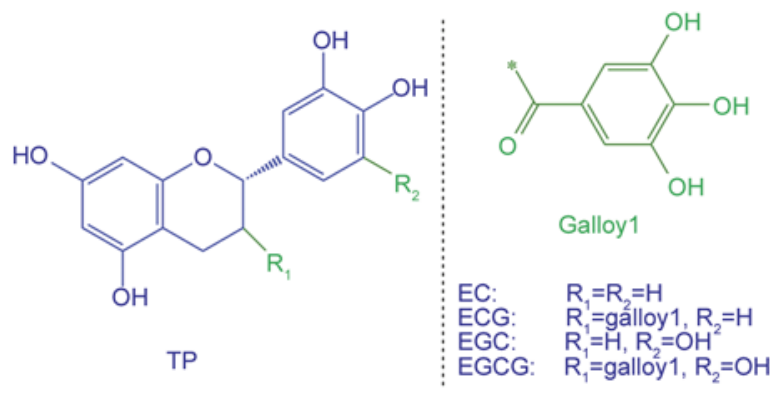

Figure 1. Chemical structure of TP

\section{Experimental}

\subsection{Materials}

PHBV with 1.09 mol\% 3-hydroxyvalerate (HV) $\left[M_{\mathrm{n}}=1.16 \cdot 10^{4} \mathrm{~g} \cdot \mathrm{mol}^{-1}, M_{\mathrm{w}} / M_{\mathrm{n}}=2.30\right]$ was obtained from Tianan Biologic Material Co., Ltd. (Ningbo, China). Tea polyphenol (TP) (polyphenols $\geq 98 \%$, catechin $\geq 80 \%$, EGCG $\geq 60 \%$, caffeinne $\leq 1.0 \%$ ) was purchased from Xuancheng Baicao Plant Industry and Trade Co., Ltd (Xuancheng, China). Chloroform and dioxane were obtained from Sinopharm Chemical Reagent Co., Ltd. (Shanghai, China) and used as received.

\subsection{Preparation of TP/PHBV composite films}

First, PHBV was completely dissolved in chloroform at $60^{\circ} \mathrm{C}$ in a three-necked flask with a magnetic stirrer. Then, the TP dioxane solutions with different mass fractions $(5,10,20,30$ and $40 \mathrm{wt} \%)$ were mixed and stirred with the PHBV solution at room temperature for $6 \mathrm{~h}$, respectively. Finally, these solutions were cast into films by an applicator. The solvent was allowed to evaporate slowly at room temperature for $48 \mathrm{~h}$, and the resulting films were further dried under vacuum drying oven at $25^{\circ} \mathrm{C}$ for another $48 \mathrm{~h}$.

\subsection{Characterization}

The tensile properties of TP/PHBV composite films were measured by an INSTRON 5969 electronic universal material testing machine (Instron Corporation, USA). Tensile specimens with $10 \mathrm{~mm}$ in width and $10 \mu \mathrm{m}$ in thickness were drawn at a strain rate of $1 \mathrm{~mm} / \mathrm{min}$. The gauge length was $50 \mathrm{~mm}$, and five replicates were run for each sample.

The hydrogen bond interactions between TP and PHBV were characterized by FT-IR spectrometer (Thermo Nicolet 8700, USA). These tests were carried out by the DTGS-MCT-A double-detector.

The crystalline structures of TP/PHBV composites were obtained with a D/Max-2550 PC diffractometer (Japan). All the samples were allowed to set aside for two weeks at room temperature to reach equilibrium crystallization. $\mathrm{CuK}_{\alpha} \mathrm{X}$-ray source was used with a wavelength $(\lambda)$ of $0.154 \mathrm{~nm}$. The angle of incidence varies from 5 to $60^{\circ}$ by steps of $0.02^{\circ}$. In order to directly understand the mobility of molecular chain of TP/PHBV composites, the crystal growth behaviors and crystalline morphologies of different composites were observed by DM2500P polarizing optical microscope with LINKAM 
LTSE350 hot stage (Leica, Germany), and the radial growth rate of spherulites was calculated by data processing software. The samples were sandwiched between two cover slides and kept at $200^{\circ} \mathrm{C}$ for $2 \mathrm{~min}$ and then cooled down to a desired isothermal crystallization temperature with a cooling rate of $30^{\circ} \mathrm{C} / \mathrm{min}$. The growth rate of spherulite was calculated by the recorded photographs which are taken at constant time intervals.

The melting and crystallization behaviors of TP/ PHBV composites were carried out by DSC (Q20, USA) with nitrogen as purging gas. Samples were firstly put on the $200^{\circ} \mathrm{C}$ hot stage for $4 \mathrm{~min}$, waited until it was fully molten and put it into liquid nitrogen. Then the thermal properties of these samples were tested. The samples were heated from -50 to $200^{\circ} \mathrm{C}$ at a rate of $10^{\circ} \mathrm{C} / \mathrm{min}$.

The contact angles of the PHBV film and TP/PHBV composite films were measured via $322 \mathrm{~W}$ contact angle analyzer (Thermo Cahn, USA) at room temperature. About $2 \mu \mathrm{L}$ deionized water was dropped on the film surface for the tests at a contact time of $5 \mathrm{~s}$. Five independent determinations at different sites of the film were averaged.

\section{Results and discussion}

\subsection{Mechanical properties of TP/PHBV composite films}

The stress-strain curves, tensile strength, and elongation at break of TP/PHBV composite films with various TP contents are shown in Figure 2. The toughness of TP/PHBV composite films increases sharply with an increase content of plant polyphenol TP. When the TP content increases from 0 to $20 \mathrm{wt} \%$, the elongation at break of TP/PHBV composite films improved from 1.5 to $36.5 \%$, with an increasing ratio of $2430 \%$. This occurs because of the hydrogen bonding interaction between phenolic hydroxyl groups in TP and carbonyl ester groups in PHBV, which may delay the failure of PHBV under the tensile stress. TP also acts as a low molecular weight plasticizer, when the TP content is lower than $5 \mathrm{wt} \%$, the tensile strength of composites tends to increase from 14.0 to $14.6 \mathrm{MPa}$. Meanwhile, the strain and elongation at break both increases by $5 \%$. However, when the TP content exceeded $10 \mathrm{wt} \%$, the tensile strength of the composite films decreased rapidly. This type of variation trend also appeared in the results of fracture work for TP/PHBV composite films. When TP content increased up to
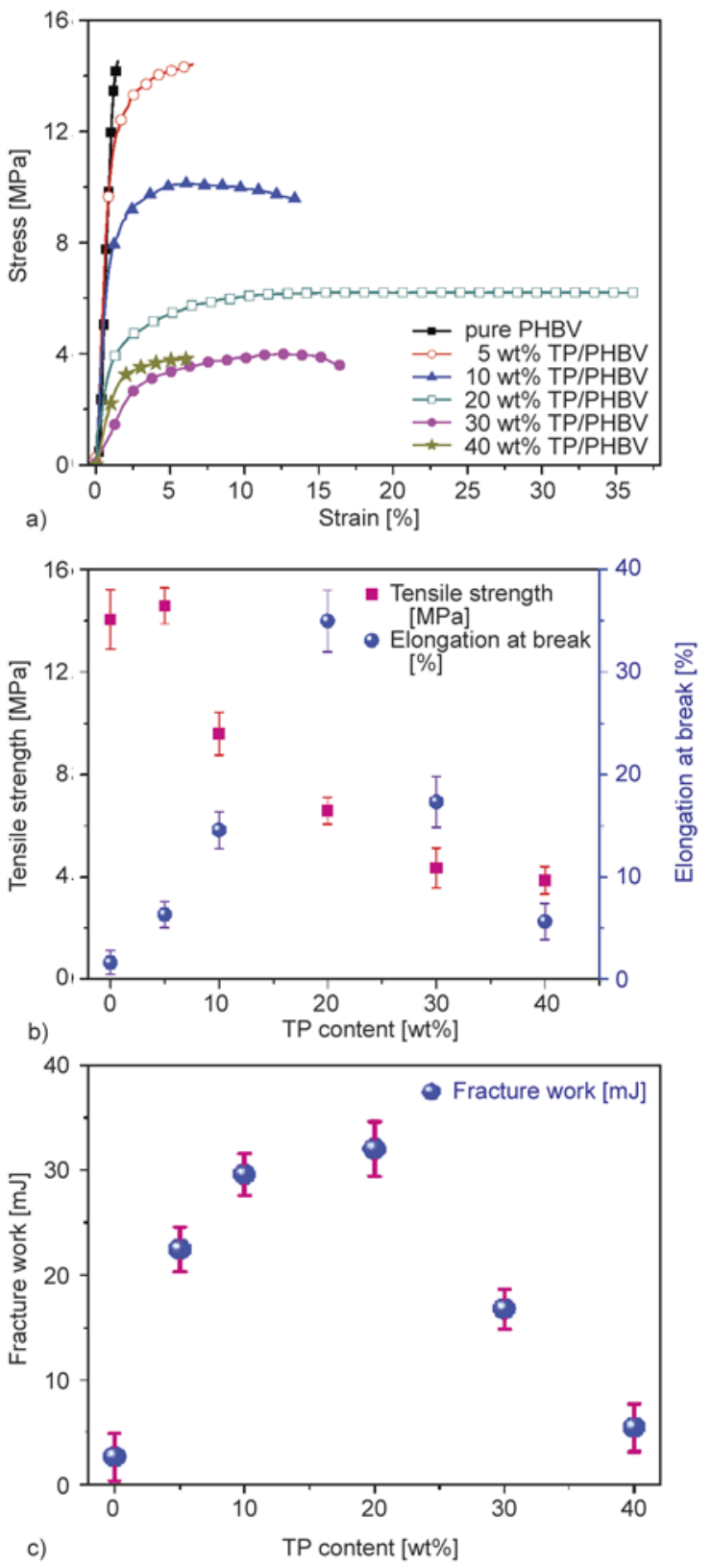

Figure 2. Stress-strain curves (a), tensile properties (b) and fracture work (c) of TP/PHBV composite films with various $\mathrm{TP}$ contents

$20 \mathrm{wt} \%$, the elongation at break of composite films reached the maximum value of $36.5 \%$, while the tensile strength decreased to $6.6 \mathrm{MPa}$. These results show that the incorporation of TP in the PHBV matrix can enhance the toughness of the composite films. When TP content exceeded $30 \mathrm{wt} \%$, the tensile strength and elongation at break of TP/PHBV composite films fell notably.

\subsection{Thermal properties of $\mathrm{TP} / \mathrm{PHBV}$ composites}

The mechanical properties of polymer materials are significantly dependent on the glass transition tem- 
perature $\left(T_{\mathrm{g}}\right)$. Because the $T_{\mathrm{g}}$ of PHBV is lower than room temperature, so secondary crystallization of its products often occur easily during storage, and resulting in the decrease of its mechanical properties. So green TP is used to improve its $T_{\mathrm{g}}$. DSC melting curves of PHBV and TP/PHBV composites is shown in Figure 3. The thermal parameters, such as $T_{\mathrm{g}}$, cold crystallization temperature $\left(T_{\mathrm{cc}}\right)$, melting temperature $\left(T_{\mathrm{m}}\right)$, cold crystallization enthalpies $\left(\Delta H_{\mathrm{cc}}\right)$, melting enthalpy $\left(\Delta H_{\mathrm{m}}\right)$, is shown in Table 1 . The degree of crystallinity $\left(X_{\mathrm{DSC}}\right)$ is also calculated by Equation (1) [23] to examine the changes caused by TP additives:

$$
X_{\mathrm{DSC}}=\frac{\Delta H_{\mathrm{f}}}{\left(1-\varphi_{\mathrm{TP}}\right) \Delta H_{\mathrm{f}}^{0}} \cdot 100 \%
$$

where $X_{\mathrm{DSC}}$ is the degree of crystallinity of PHBV and its composites, $\varphi_{\mathrm{TP}}$ is the weight fraction of TP, $\Delta H_{\mathrm{f}}$ is the measured melting enthalpies and $\Delta H_{\mathrm{f}}^{0}$ is the enthalpies of $100 \%$ crystalline PHBV, which is chosen as $146.6 \mathrm{~J} \mathrm{~g}^{-1}$ for PHB.

In Figure 3 and Table 1, with the TP content increasing from 0 to $40 \mathrm{wt} \%$, the $T_{\mathrm{g}}$ improved from 1.8 to

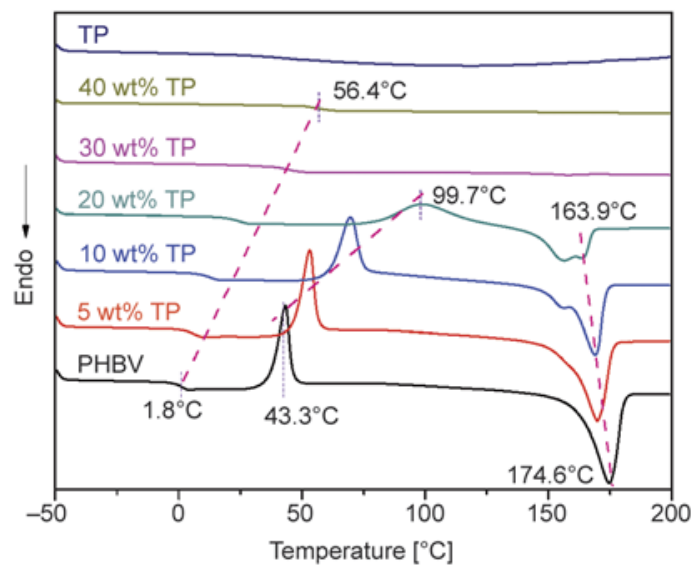

Figure 3. DSC melting curves of $\mathrm{PHBV}$ and TP/PHBV composites $56.4^{\circ} \mathrm{C}$, increasing by $54.6^{\circ} \mathrm{C}$. The cold crystallization temperature increased from 43.4 to $109.5^{\circ} \mathrm{C}$, and the melting temperature decreased from 174.6 to $157.7^{\circ} \mathrm{C}$. These maybe occurred by the formation of the intermolecular hydrogen bonding interaction. As an effect of adding TP component on PHBV, its composites showed a single glass transition temperature and the lower melting point temperature. Moreover, the $T_{\mathrm{g}}$ was increased accordingly.

The crystallinity of TP/PHBV composites also calculated by the change of enthalpies and are also shown in Table 1 . The crystallinity of composites decreases with the increase of TP content. The decrease of crystallinity maybe influenced by hydrogen bonding interaction between PHBV and TP, which restricts the motion ability of molecular chain.

Figure 4 shows the crystallize patterns of PHBV and $\mathrm{TP} / \mathrm{PHBV}$ composites at $40^{\circ} \mathrm{C}$, respectively. In Figure $4 \mathrm{a}$, the pure PHBV spherulites display the well-known Maltese cross extinction pattern and the concentric extinction rings with the radial growth rate of $1.08 \mu \mathrm{m} / \mathrm{s}$. When the TP contents was $5 \mathrm{wt} \%$, 'Maltese cross' extinction pattern also appeared in composite, however the banded pattern changed to radial pattern. Moreover, the spherulite radius and the radial growth rate decreased with an increase of TP content. When the TP content reached $20 \mathrm{wt} \%$, spherulite formation can't be observed resulting from the arrangement and the growth modes of spherulites lamellar layers, which are depending on polymer aggregate structure at the same isothermal crystallization temperature and degree of supercooling. The banded spherulites for PHBV generate band pattern of dark and light, which can be related to twisting period of the spherulites radial growth corresponding to extinction spacing, and the adjacent lamellar layers keep

Table 1. Thermal parameters of PHBV and TP/PHBV composites

\begin{tabular}{|c|c|c|c|c|c|c|c|}
\hline Sample & $\begin{array}{c}\mathbf{T}_{\mathbf{g}} \\
{\left[{ }^{\circ} \mathbf{C}\right]}\end{array}$ & $\begin{array}{l}\mathbf{T}_{\mathrm{cc}}{ }^{\mathbf{a}} \\
{\left[{ }^{\circ} \mathbf{C}\right]}\end{array}$ & $\begin{array}{c}\Delta \mathbf{H}_{\mathbf{c c}} \\
{\left[\mathbf{J} \cdot \mathbf{g}^{-1}\right]}\end{array}$ & $\begin{array}{c}\mathbf{T}_{\mathbf{m}} \\
{\left[{ }^{\circ} \mathbf{C}\right]}\end{array}$ & $\begin{array}{c}\Delta \mathbf{H}_{\mathbf{m}} \\
{\left[\mathbf{J} \cdot \mathbf{g}^{-1}\right]}\end{array}$ & $\begin{array}{c}\mathbf{X}_{\text {DSC }}{ }^{b} \\
{[\%]}\end{array}$ & $\begin{array}{c}\mathbf{X}_{\text {WXRD }}{ }^{c} \\
{[\%]}\end{array}$ \\
\hline Pure PHBV & 1.81 & 43.28 & 36.13 & 174.61 & 89.12 & 61.04 & 53.03 \\
\hline $5 \mathrm{wt} \% \mathrm{TP} / \mathrm{PHBV}$ & 6.36 & 53.08 & 37.83 & 169.89 & 80.34 & 57.92 & 48.83 \\
\hline $10 \mathrm{wt} \%$ TP/PHBV & 12.81 & 69.64 & 39.16 & 169.01 & 73.88 & 56.23 & 41.32 \\
\hline $20 \mathrm{wt} \%$ TP/PHBV & 24.80 & 99.74 & 37.76 & 163.88 & 50.43 & 43.18 & 40.72 \\
\hline $30 \mathrm{wt} \%$ TP/PHBV & 45.67 & 109.45 & - & 157.69 & 1.05 & 1.03 & 38.05 \\
\hline $40 \mathrm{wt} \%$ TP/PHBV & 56.35 & - & - & - & - & - & 31.64 \\
\hline Pure TP & - & - & - & - & - & - & 8.19 \\
\hline
\end{tabular}

${ }^{\mathrm{a}} T_{\mathrm{cc}}$ is the cold crystallization temperature.

${ }^{b}$ Determined from DSC enthalpy parameters.

'Determined from WXRD spectra 

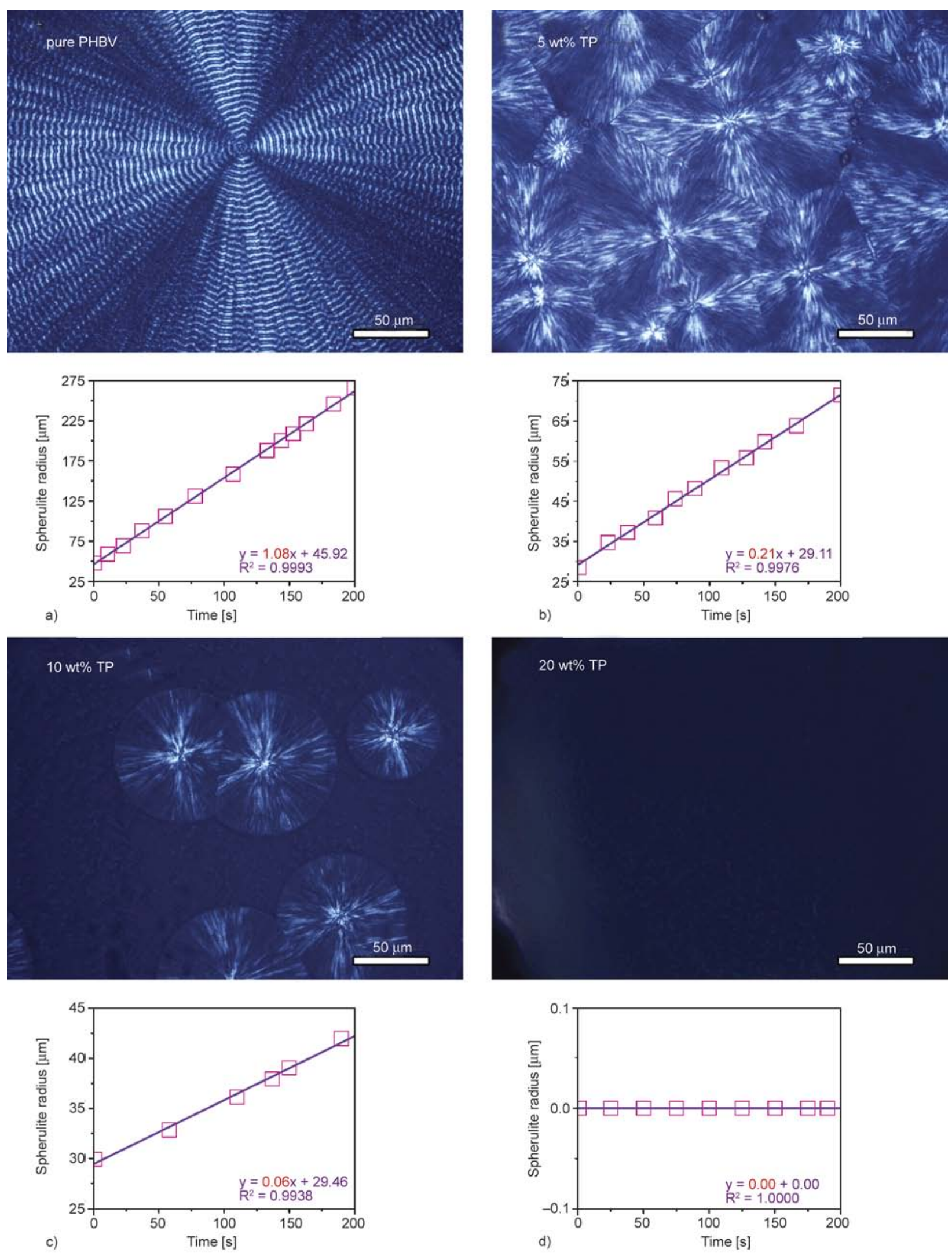

Figure 4. Crystalline morphology and radial growth rate of the spherulites of PHBV (a) and TP/PHBV composites (b) $5 \mathrm{wt} \% \mathrm{TP} / \mathrm{PHBV}$, (c) $10 \mathrm{wt} \% \mathrm{TP} / \mathrm{PHBV}$ and (d) $20 \mathrm{wt} \% \mathrm{TP} / \mathrm{PHBV}$ at a constant temperature of $40^{\circ} \mathrm{C}$

the same period and phase to twist. In the TP/PHBV composites, TP component as organic rigid toughening material plays the role of the proton-donating material. The intermolecular hydrogen bonding interaction restricts molecular chain motion on PHBV component, and break coordination effect of 
lamellae layers of the PHBV spherulites radial growth. As a result, banded spherulite patterns were replaced by radial patterns.

\subsection{Hydrophilic-hydrophobic properties of TP/PHBV composites}

In order to preliminary study on the application of TP/PHBV composite films, contact angle with water of pure PHBV film and TP/PHBV composite film with various TP contents are shown in Figure 5. The contact angle of TP/PHBV composite films showed a decreasing trend with the increase of TP content, from 97.3 to $54.2^{\circ}$. It can be explained by the hydrophilic interaction for phenolic hydroxyl groups in natural polyphenol TP. In the TP/PHBV composite films, some phenolic hydroxyl groups were exposed on the film surface and changed the surface tension of composite film, which accounted for the improvement of its hydrophilicity. On the other side, biocompatible TP has strong sterilizing

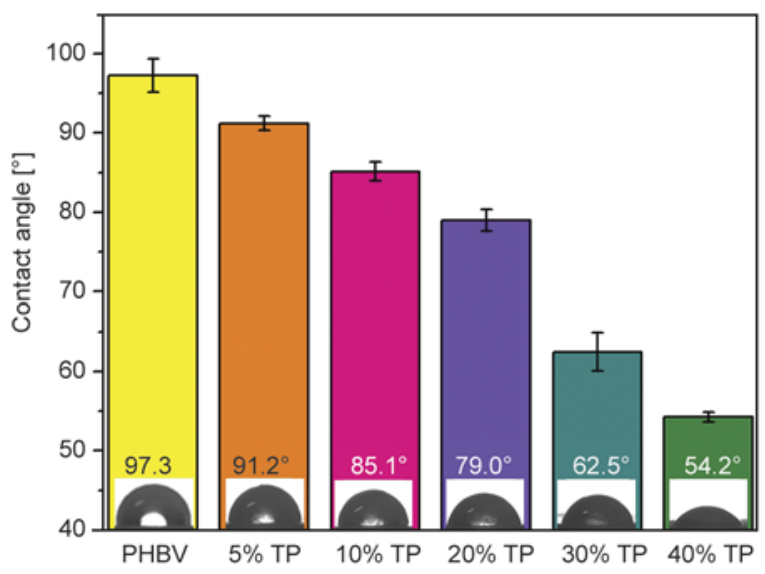

Figure 5. Contact angle of pure PHBV film and TP/PHBV composite films with various TP contents

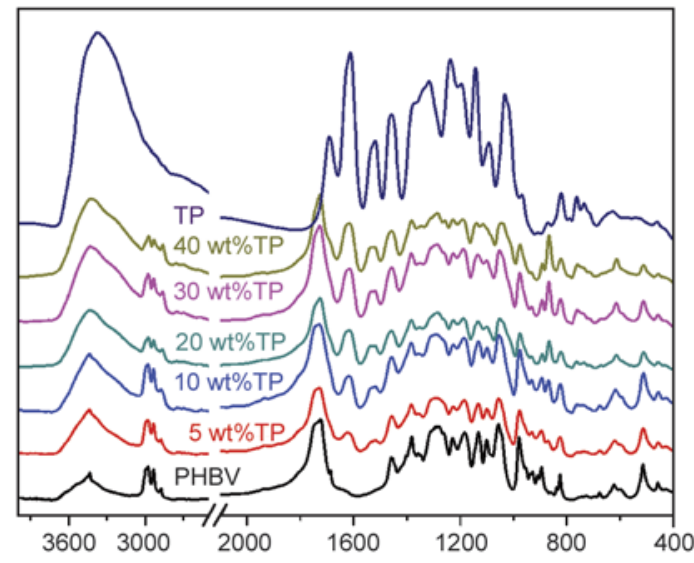

a)

Wavenumbers $\left[\mathrm{cm}^{-1}\right]$ function, which should be attributed to the $\alpha$-phenylbenzopyran structure in TP. With the combination of above advantages, it is expected that the TP/ PHBV composites possess some promising applications in biomedical fields.

\subsection{Intermolecular interactions of $\mathrm{TP} / \mathrm{PHBV}$ composites}

For a better understanding of the hydrogen bonding interaction between TP and PHBV, the FT-IR was used to observe the change of absorption peaks of characteristic groups. Figure 6 shows the FT-IR spectra of TP/PHBV composites, with the stretching vibrations of hydroxyl $\left(v_{\mathrm{O}-\mathrm{H}}\right)$ and carbonyl $\left(v_{\mathrm{C}=\mathrm{O}}\right)$ groups. All the characteristic absorption peaks of PHBV and TP appear in TP/PHBV composites, while the positions of hydroxyl and carbonyl stretching vibration peaks have changed. TP shows one broad band, centered at $3380 \mathrm{~cm}^{-1}$, which attributed to the phenolic hydroxyl stretching vibration. For pure PHBV, only a weak peak band centered at $3440 \mathrm{~cm}^{-1}$ is observed in this region, which should be attributed to the stretching of the chainend hydroxyl groups [24]. In Figure 6b, a new band appears at about $3250 \mathrm{~cm}^{-1}$ which presumably was induced by the formation of inter-molecular hydrogen bonding between TP and PHBV.

To illustrate hydrogen bonding interaction, the carbonyl $\left(v_{\mathrm{C}=0}\right)$ stretching vibration band in the range from 1660 to $1800 \mathrm{~cm}^{-1}$ was analyzed. As is shown in Figure 6b, the peak band around $1722 \mathrm{~cm}^{-1}$ should be attributed to the crystalline region of the car bonyl group of PHBV, which is very clear for neat PHBV, and the peak at around $1746 \mathrm{~cm}^{-1}$ to the amorphous region of the carbonyl group $[22,25$,

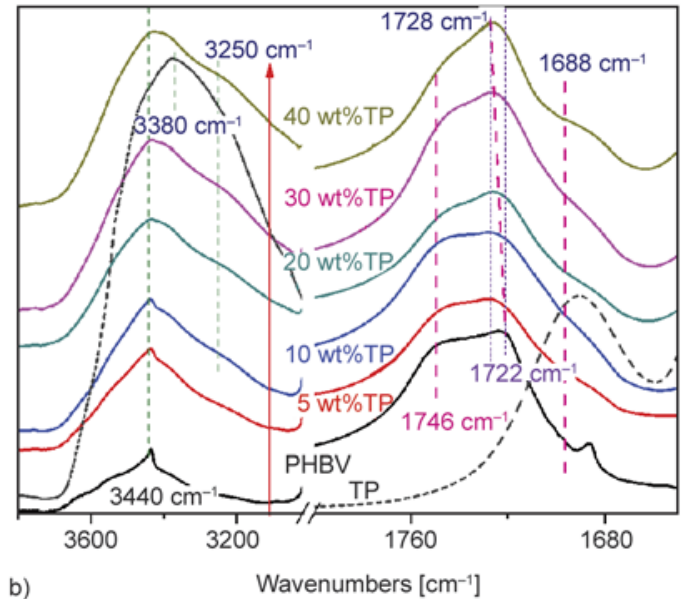

Figure 6. FT-IR spectra of TP/PHBV composites (a), hydroxyl stretching region and carbonyl stretching region in the range of $3800 \sim 3000$ and $1800 \sim 1650 \mathrm{~cm}^{-1}$ (b) 
26]. When the PHBV is blended with TP, a new band appears at lower wave-number about $1688 \mathrm{~cm}^{-1}$. This new band is assigned to the hydrogen-bonded carbonyl groups. With the increase of the TP content, the carbonyl peak position for parts of crystalline region of the carbonyl group is shifting from 1722 to $1728 \mathrm{~cm}^{-1}$, whereas that parts of the free $\mathrm{C}=\mathrm{O}$ group is almost invariable. This suggested that the hydrogen bonding interaction is formed between the phenolic hydroxyl and carboxyl groups, which is consistent with the results of hydroxyl $\left(v_{\mathrm{O}-\mathrm{H}}\right)$ stretching vibration band.

\subsection{Crystalline structure of TP/PHBV composites}

The physical properties of polymer composite films not only depend on the intermolecular force but also on the degree of crystallinity. The effect of addition TP component on PHBV crystal structure was characterized by WAXD, and the patterns of PHBV and TP/PHBV composites are shown in Figure 7. The diffraction peaks of (020), (110), (021), (101), (111), (121), (040) and (002) for PHBV crystal face appeared in WXRD patterns. And the TP did not significantly affect the diffraction peak position of TP/ PHBV composites. This indicates that the introduction of the TP component in composites doesn't change the crystal structure of PHBV. From Figure 7 and Table 1, the crystallinity of PHBV component decreases with an increase in TP content, reducing from 53 to $32 \%$. The decrease of crystallinity maybe influenced by hydrogen bonding interaction between PHBV and TP, which is consistent with the results discussed in DSC.

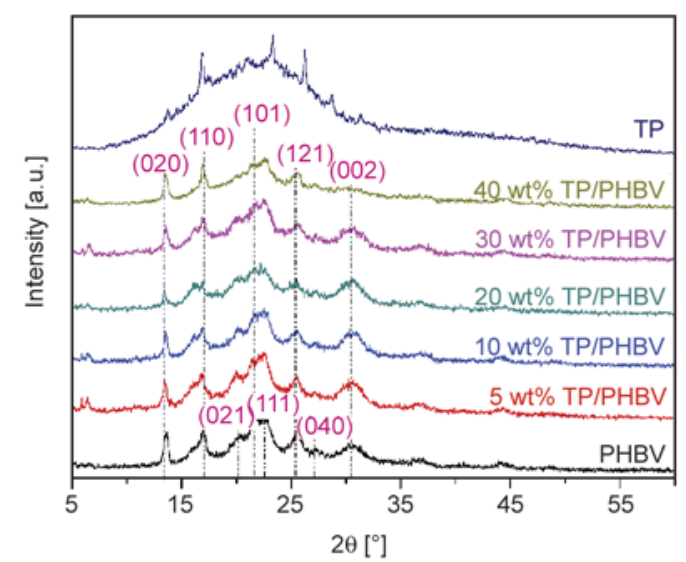

Figure 7. XRD patterns of PHBV and TP/PHBV composites

\section{Conclusions}

Biodegradable TP/PHBV composites were prepared with green TP and bacterial polyester PHBV. The intermolecular hydrogen bonding interactions in composites were confirmed through the shift of hydroxyl $\left(v_{\mathrm{O}-\mathrm{H}}\right)$ and carbonyl $\left(v_{\mathrm{C}=\mathrm{O}}\right)$ stretching vibration peaks. By adding TP components to PHBV matrix, the mechanical and thermal properties of TP/PHBV composite films were improved. Compared with pure PHBV, the elongation at break increased 24 times, meanwhile, the glass transition temperature and cold crystallization peak temperature increased by almost 45 and $45^{\circ} \mathrm{C}$, respectively. The hydrophilicity of TP/PHBV composites can be controlled through adjusting the dosage of TP. Therefore, the result of this composite system will have an important effect on broadening the green plant polyphenol application and expanding the modification methods for preparing fully biodegradable environmental-friendly bacterial polyester materials.

\section{Acknowledgements}

This research is financially supported by the National Natural Science Foundation for Distinguished Young Scholar of China (50925312), The Program for Changjiang Scholars and Innovative Research Team in University (T2011079, IRT1221), the National Natural Science Foundation of China (50873022), the Program of Talents of Discipline to University (111-2-04), the Specialized Research Fund for the Doctoral Program of Higher Education (20100075110007) and the Chinese Universities Scientific Fund (CUSF-DH-D-2013007).

\section{References}

[1] Adamus G., Sikorska W., Kowalczuk M., Montaudo M., Scandola M.: Sequence distribution and fragmentation studies of bacterial copolyester macromolecules: Characterization of PHBV macroinitiator by electrospray ion-trap multistage mass spectrometry. Macromolecules, 33, 5797-5802 (2000). DOI: $10.1021 / \mathrm{ma} 000005 \mathrm{~g}$

[2] Zhu B., Li J., He Y., Yoshie N., Inoue Y.: Hydrogenbonding interaction and crystalline morphology in the binary blends of poly( $\varepsilon$-caprolactone) and polyphenol catechin. Macromolecular Bioscience, 3, 684-693 (2003).

DOI: $10.1002 / \mathrm{mabi} .200350034$

[3] Serpell C. J., Cookson J., Ozkaya D., Beer P. D.: Core@shell bimetallic nanoparticle synthesis via anion coordination. Nature Chemistry, 3, 478-483 (2011). DOI: $10.1038 /$ nchem. 1030 
[4] Wang L., Wang X. J., Zhu W. F., Chen Z. F., Pan J. Y., $\mathrm{Xu}$ K. T.: Effect of nucleation agents on the crystallization of poly(3-hydroxybutyrate-co-4-hydroxybutyrate) (P3/4HB). Journal of Applied Polymer Science, 116, 1116-1123 (2010).

DOI: 10.1002/app.31588

[5] Carli L. N., Crespo J. S., Mauler R. S.: PHBV nanocomposites based on organomodified montmorillonite and halloysite: The effect of clay type on the morphology and thermal and mechanical properties. Composites Part A: Applied Science and Manufacturing, 42, 1601-1608 (2011).

DOI: 10.1016/j.compositesa.2011.07.007

[6] Kaur J., Lee J. H., Shofner M. L.: Influence of polymer matrix crystallinity on nanocomposite morphology and properties. Polymer, 52, 4337-4344 (2011).

DOI: $10.1016 /$ j.polymer.2011.07.020

[7] Sridhar V., Lee I., Chun H. H., Park H.: Graphene reinforced biodegradable poly(3-hydroxybutyrate-co-4hydroxybutyrate) nano-composites. Express Polymer Letters, 7, 320-328 (2013).

DOI: $10.3144 /$ expresspolymlett.2013.29

[8] Zhang R., Huang H., Yang W., Xiao X., Hu Y.: Preparation and characterization of bio-nanocomposites based on poly(3-hydroxybutyrate-co-4-hydroxybutyrate) and CoAl layered double hydroxide using melt intercalation. Composites Part A: Applied Science and Manufacturing, 43, 547-552 (2012).

DOI: $10.1016 /$ j.compositesa.2012.01.005

[9] Dagnon K. L., Robinson C., Chen H. H., Garrett D. C., Innocentini-Mei L. H., D'Souza N. A.: Layer double hydroxides for enhanced poly(3-hydroxybutyrate-co3-hydroxyvalerate) crystallization. Journal of Applied Polymer Science, 127, 3395-3406 (2013).

DOI: $10.1002 /$ app.37646

[10] Schacher F. H., Rupar P. A., Manners I.: Functional block copolymers: Nanostructured materials with emerging applications. Angewandte Chemie International Edition, 51, 7898-7921 (2012).

DOI: $10.1002 /$ anie. 201200310

[11] Patrício P., Pereira F. V., dos Santos M. C., de Souza P. P., Roa J. P. B., Orefice R. L.: Increasing the elongation at break of polyhydroxybutyrate biopolymer: Effect of cellulose nanowhiskers on mechanical and thermal properties. Journal of Applied Polymer Science, 127, 3613-3621 (2013).

DOI: $10.1002 / a p p .37811$

[12] Sadik T., Massardier V., Becquart F., Taha M.: Polyolefins/poly(3-hydroxybutyrate-co-hydroxyvalerate) blends compatibilization: Morphology, rheological, and mechanical properties. Journal of Applied Polymer Science, 127, 1148-1156 (2013).

DOI: $\underline{10.1002 / a p p .37957}$
[13] Naguib H. F., Aziz M. S. A., Saad G. R.: Synthesis, morphology and thermal properties of polyurethanes nanocomposites based on poly(3-hydroxybutyrate) and organoclay. Journal of Industrial and Engineering Chemistry, 19, 56-62 (2013).

DOI: $10.1016 /$ j.jiec.2012.06.023

[14] Araujo P. L. B., Ferreira C. R. P. C., Araujo E. S.: Biodegradable conductive composites of poly(3-hydroxybutyrate) and polyaniline nanofibers: Preparation, characterization and radiolytic effects. Express Polymer Letters, 5, 12-22 (2011).

DOI: 10.3144 /expresspolymlett.2011.3

[15] Hinüber C., Häussler L., Vogel R., Brünig H., Heinrich G., Werner C.: Hollow fibers made from a poly(3hydroxybutyrate)/poly- $\varepsilon$-caprolactone blend. Express Polymer Letters, 5, 643-652 (2011). DOI: $10.3144 /$ expresspolymlett.2011.62

[16] Mousavioun P., George G. A., Doherty W. O. S.: Environmental degradation of lignin/poly(hydroxybutyrate) blends. Polymer Degradation and Stability, 97, 11141122 (2012). DOI: $10.1016 /$ j.polymdegradstab.2012.04.004

[17] Zhao Q., Wang S., Kong M., Geng W., Li R. K. Y., Song C., Kong D.: Phase morphology, physical properties, and biodegradation behavior of novel PLA/ PHBHHx blends. Journal of Biomedical Materials Research Part B: Applied Biomaterials, 100, 23-31 (2012).

DOI: $10.1002 / \mathrm{jbm} . b .31915$

[18] Nagarajan V., Misra M., Mohanty A. K.: New engineered biocomposites from poly(3-hydroxybutyrateco-3-hydroxyvalerate) (PHBV)/poly(butylene adipateco-terephthalate) (PBAT) blends and switchgrass: Fabrication and performance evaluation. Industrial Crops and Products, 42, 461-468 (2013).

DOI: $10.1016 /$ j.indcrop.2012.05.042

[19] Ma P., Hristova-Bogaerds D. G., Lemstra P. J., Zhang Y., Wang S.: Toughening of PHBV/PBS and PHB/PBS blends via in situ compatibilization using dicumyl peroxide as a free-radical grafting initiator. Macromolecular Materials and Engineering, 297, 402-410 (2012). DOI: 10.1002/mame.201100224

[20] Miller S. A., Billington S. L., Lepech M. D.: Improvement in environmental performance of $\operatorname{poly}(\beta$-hydroxybutyrate)-co-( $\beta$-hydroxyvalerate) composites through process modifications. Journal of Cleaner Production, 40, 190-198 (2013).

DOI: $10.1016 /$ j.jclepro.2012.08.033

[21] Hsieh Y. T., Woo E. M.: Phase diagrams in blends of poly(3-hydroxybutyric acid) with various aliphatic polyesters. Express Polymer Letters, 5, 570-580 (2011).

DOI: $10.3144 /$ expresspolymlett.2011.56 
[22] Zhu B., Li J., He Y., Inoue Y.: Studies on binary blends of poly(3-hydroxybutyrate-co-3-hydroxyhexanoate) and natural polyphenol catechin: Specific interactions and thermal properties. Macromolecular Bioscience, 3, 258-267 (2003).

DOI: $10.1002 / \mathrm{mabi} .200390036$

[23] Shan G-F., Gong X., Chen W-P., Chen L., Zhu M-F.: Effect of multi-walled carbon nanotubes on crystallization behavior of poly(3-hydroxybutyrate-co-3hydroxyvalerate). Colloid and Polymer Science, 289, 1005-1014 (2011).

DOI: $10.1007 / \mathrm{s} 00396-011-2412-1$
[24] Xiang H., Wang S., Wang R., Zhou Z., Peng C., Zhu M.: Synthesis and characterization of an environmentally friendly PHBV/PEG copolymer network as a phase change material. Science China Chemistry, 56, 716-723 (2013).

DOI: 10.1007/s11426-013-4837-5

[25] Yu H-Y., Qin Z-Y., Liu Y-N., Chen L., Liu N., Zhou Z.: Simultaneous improvement of mechanical properties and thermal stability of bacterial polyester by cellulose nanocrystals. Carbohydrate Polymers, 89, 971-978 (2012).

DOI: $10.1016 /$ j.carbpol.2012.04.053

[26] Fei B., Chen C., Wu H., Peng S., Wang X., Dong L.: Quantitative FTIR study of PHBV/bisphenol A blends. European Polymer Journal, 39, 1939-1946 (2003).

DOI: $10.1016 / \mathrm{s} 0014-3057(03) 00114-9$ 